EGU2020-20689

https://doi.org/10.5194/egusphere-egu2020-20689

EGU General Assembly 2020

(c) Author(s) 2021. This work is distributed under

the Creative Commons Attribution 4.0 License.

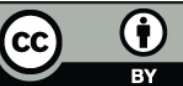

\title{
Modelling the impact of changing riverine permafrost input on an Arctic coastal ecosystem
}

\author{
Michael Bedington ${ }^{1}$, Ricardo Torres ${ }^{1}$, Luca Polimene ${ }^{1}$, Paul Mann ${ }^{2}$, and Jens Strauss ${ }^{3}$ \\ ${ }^{1}$ Plymouth Marine Laboratory, Plymouth, United Kingdom (mbe@pml.ac.uk) \\ ${ }^{2}$ Northumbria University, Newcastle, United Kingdom \\ ${ }^{3}$ Alfred Wegener Institute, Potsdam, Germany
}

The Arctic ocean receives $11 \%$ of the global river discharge and the Arctic rivers drain large permafrost rich catchments. Where these rivers outflow into the marginal shelf seas of the Arctic ocean the terrestrial dissolved organic matter (tDOM) which they transport has an important role to play in the coastal ecosystem. This tDom is derived from inland permafrost and as it thaws under future climate scenarios there are expected to be changes to both the composition and quantity of riverine tDOM. At the same time there will be changes to the seasonality and magnitude of river discharge, due to increased precipitation and earlier snow melt, and to the light availability, due to reduced seasonal sea ice. To understand the possible impact of these changes on the coastal ecosystem it is important to understand the present role of permafrost derived tDOM and the possible changes to the nearshore circulation.

We model the hydrodynamics of the extensive shallow shelf of the Laptev sea, into which drains the Lena river - the $13^{\text {th }}$ largest in the world by discharge. The output from the hydrodynamic model is used to drive the ecosystem model ERSEM which has been adapted to explicitly include a permafrost tDOM input. This coupled model system allows us to investigate both the role of present day tDOM in an Arctic coastal ecosystem and to hypothesise on the impact of increases in future. In particular we attempt to quantify the efficacy of the microbial carbon pump under different tDOM inputs. 